\title{
Increasing Efficiency in Academia: The Use of a Weaning Model in Fundraising
}

Received (in revised form): September 14, 2004

\section{Vincent M. Maniaci}

Dr. Maniaci has been the Vice President for Institutional Advancement at Bellarmine University since 1997. He also teaches in Bellarmine's undergraduate core program and has an appointment to the University's Rubel School of Business where he teaches in the MBA program. The article was adapted from his doctoral dissertation at the University of Pennsylvania GSE. He received the Grenzebach Award for Outstanding Dissertation in the field of Philanthropy for Education in 2003.

\section{Rob Poole}

Dr. Poole graduated from Texas A\&M with a BS in Economics where he was commissioned in the Marine Corps and was stationed all around the world. Returning to the United States, he went to USC for a master's degree in systems management. Later he obtained a Ph.D. in operations management and has taught at several schools, including the University of North Texas, Central Missouri State University, and Bellarmine University, where he led the MBA program. He researches and consults on a variety of interests including education reform, fund raising and other applied process improvements, and is now a faculty member at Richard Stockton College in New Jersey.

\begin{abstract}
The authors discuss a method to increase institutional efficiency and financial stability through strategic planning, by gradually reallocating funds raised for annual operations to quasi-endowment over a period of years using a weaning model. The weaning model is offered as a tactic to address issues of financial vulnerability developed in earlier studies by Maniaci and Poole.
\end{abstract}

\footnotetext{
Author's Contact Address:

Vincent M. Maniaci

Vice President for Institutional Advancement

Bellarmine University

2001 Newburg Road

Louisville, KY 40205, USA

Phone: +502 452-8328

Fax: +502 4528337

Email: vmaniaci@bellarmine.edu
}

\section{Keywords:}

resource allocation, efficiency, revenue, cost control, mission, strategic planning

\section{Introduction}

As the economy softens and the challenges for higher education intensify, efficiency will play a greater role in managing colleges and universities. Indeed, efficiency has become the darling among academic management vernacular, and for good reason. According to data from National Center for Education Statistics, over 500 nonprofit colleges closed from 1969 to $2001 .^{1}$ This trend is likely to continue and perhaps escalate if academic decision-makers fail to pay attention to the effects of inefficient reliance on revenue streams from fund raising for operating support.

In the 1980s institutions increased 
tuition revenue and placed excess revenues from the increased value of endowments into construction and financial aid. This allowed many boards and administrations to avoid two difficult tasks: directly raising funds for endowment and annual giving for current operations and controlling spending. ${ }^{2}$

Although some boards and administrations may have relaxed their efforts to raise money and control expenses, the bull markets of the 1980s and 1990s increased net revenues by generating more unrestricted gifts and expanding endowments. As a result, institutions expanded. However, capital markets have since slowed. Inevitably the core of higher education has come to rely on undergraduate tuition as its primary income stream. ${ }^{3}$

The tuition dependence of the smaller, meagerly endowed, private institutions are particularly vulnerable to changes in the student market. In comparison, market competition in enrollment and fund raising favors stronger and larger institutions. To survive in this changing environment, the small private institutions must change the way they generate revenues relative to their costs.

Unfortunately, many institutions do not integrate their strategic planning process effectively. The budget operationalizes the strategic planning of the institution. That starts with aligning their mission to the environment. The purpose of this paper is to discuss how private master degree granting universities can become more efficient by strategically planning for surplus in gifts for current operations and by investing that surplus in endowment.

\section{Strategic Mission}

Institutions operate at different levels of efficiency. At one extreme are institutions with unrealistic missions, poor strategic plans, and budgets determined arbitrarily or driven by exigency. On the other end of the spectrum are those with realistic missions and strategic plans reinforced by budgets that align priorities with resources. Most are somewhere in between those extremes.

Data taken from the Higher Education Price Index indicates that inflation in higher education has been approximately 14 percent from 1996 to 2000 . This is to say, if an institution running at optimum efficiency maintained a steady state of operations during that period, its costs must still increase by 14 percent if they are to continue that steady state of operations. ${ }^{4}$

Conversely, an institution with suboptimum efficiency could conceivably maintain a steady state of operation without an increase in revenue if it reallocates resources more efficiently. The inefficient institution must take money away from suboptimum operations to fund the increases needed in other required areas. Figure 1 illustrates the point of efficiency at which an institution must increase revenue to continue a steady state of operation.

\section{Zemsky-Massy Balanced Budget Model}

Zemsky and Massy discuss three separate models used to balance budgets, each of which should be used in the annual budget process: decreased cost, increased revenue, and reallocation of resources. Each can be successful to balance the budget; however, efficiency can be improved by cost reduction and resource allocation, whereas increasing revenue tends to dull the incentive to increase efficiency. ${ }^{5}$

The efficient institution achieves its mission and goals-including excellence 


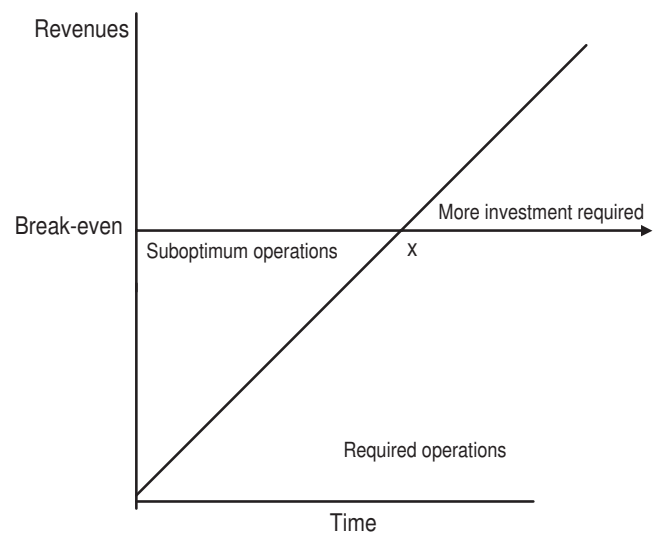

Figure 1: Efficiency and revenue

and prestige-with minimal expenditure levels. Benchmarking operations to similar institutions can help measure how efficient an organization is, but the success of missions and the degree of efficiency are often known only in the long run.

\section{Cost Control}

There are several reasons for the dramatic increase in higher education costs over the last two decades. Colleges and universities are labor intensive, and much of the increase in cost is related to faculty and administrators. Colleges try to maintain salaries at least at the rate of inflation and to accommodate the soaring cost of health-care insurance. Other factors include deferred maintenance and the high cost and functional obsolescence of new technology.
The cost control model works best for institutions that are not spending money wisely and/or operating efficiently. For institutions running at or near efficiency, continued cost control without an increase in revenue will eventually erode institutional ability to grow. Examples of cost control are shown in Table 1 .

\section{Increased Revenue}

Tuckman and Chang (1992) assume that nonprofit decision-makers have an incentive to earn accumulated surpluses. They sought to determine the charitable contribution of nonprofits and how much charity these organizations must provide to maintain their status. Their model assumes that the satisfaction of decision makers is dependent on both the level of their program operations and on the level of their equity, and that each of these requires surplus revenue. They define net revenue as being the surplus of a nonprofit that results when its revenues exceed its expenditures in a given year. There is a distinction between economic surplus for profit, whereby revenue is greater than expenses, and accounting surplus for nonprofit, whereby any surplus is absorbed into the institution as accumulated equity. ${ }^{6}$

Equity or net worth of a nonprofit may be accumulated over time. It indicates the difference between assets and liabilities. ${ }^{7}$ Equity, in the form of liquid or semiliquid assets, provides protection against temporary downturns in revenue

Table 1: Cost control examples

\begin{tabular}{lll}
\hline Problem & Action & Limit \\
\hline $\begin{array}{l}\text { Full-time faculty cost } \\
\text { Breadth of programs }\end{array}$ & Use adjuncts & May affect quality, accreditation \\
Faculty per student & Reduce number of classes & May delay some students graduation \\
& Increase class size & May limit student participation \\
\end{tabular}


and unexpected spikes in expenditures or declines in gifts, donations, and government grants. Unexpected declines can be especially threatening when they appear in enrollment at institutions that are tuition-dependent. An increase in equity both reduces the vulnerability of the nonprofit and increases the security level of its decision makers. ${ }^{8}$

The tendency of the competitive market of higher education will push all institutions to consume any surplus revenue. Indeed, one can argue that a nonprofit should not have surplus revenue precisely because of its status as nonprofit. Surplus revenue can be used as a source of subsidy to those unable to afford the cost of tuition, as a hedge against financial uncertainty and risk, as a means to decrease dependence from the marketplace, and as a measure of financial success. ${ }^{9}$

Increasing revenue at an institution with a poor mission and strategic plan or at one with a poor budget process may work temporarily, but eventually these weaknesses will start to affect program offerings and enrollment. At this point it should become increasingly difficult to continue to increase revenue. Increased spending at such an institution may be akin to throwing good money after bad, unless the institution is able to spend money for current operations to improve market position, which would enhance future tuition revenue and gift prospects. The institution must re-evaluate its mission, strategic plan, and budget process, or risk increasing vulnerability and failure.

\section{Reallocation of Resources}

In a university context of diminishing resources, the greatest risk is to stop growing, to survive by indiscriminately under-financing all fields of activity.
And it is false to believe that development necessarily implies additional resources or expansion. Growth does not necessarily mean more money. This can very well come about through the redistribution of resources, greater productivity, and the systematic search for quality and excellence. ${ }^{10}$

This is a key distinction. Growth defined as innovation and adaptation is necessary to avoid stagnation, but top-line revenue growth is not. On the other hand, while this does not necessarily imply additional revenue, the rising cost due to inflation alone will result in rising expenditures each year for an institution that is operating at optimum efficiency. The recognition of this difference is the hallmark of a good strategic planning process.

Practically, there are many institutions that have unrealistic missions, poor strategic plans, and/or a poorly operationalized mission and plan. These institutions are capable of maintaining or improving operations through reallocation of expenditures, but generating more resources and applying them toward a dysfunctional mission or strategic plan may impair an institution in the long run. They must become more productive by seeking out competitive programs and curriculum offerings. Further, they must look hard at resource allocation and be willing to re-engineer their operations with an eye toward eliminating nonvalue added processes.

\section{Impact of Allocation Decisions}

Institutions must decide on the highest and best use of revenues. The standard alternatives are: (1) use the money to increase the operating budget, (2) use the money to fund a current expenditure in a one-time manner, (3) construct new 
facilities, (4) place the money in quasiendowment.

If the money is put into the operating budget, there is an immediate utility benefit, but arbitrarily adding gift revenue to existing accounts may mask the efficiency of the current mix of programs. This may create an expenditure level that cannot be maintained. ${ }^{11}$

Funding a current expenditure in a one-time manner may be a good investment, as would construction of a new facility; however, these types of uses are irreversible, and unless the windfall is significant it may not be enough to cover the entire cost of the project. Further, new facilities often increase future operating expenses.

As a hedge against inflation, increasing equity in quasi-endowment protects institutions from temporary downturns in revenue, unexpected spikes in expenditures, and/or unplanned declines in gifts. The availability of replacement funds provides security and reduces the need to make budget changes during the fiscal year. $^{12}$

The smaller the balances, of unrestricted and restricted expendablefunds and of the funded self-insurance reserves, the more important quasiendowment is for liquidity. Liquidity is a key factor in relation to financial vulnerability and an institution's capacity for growth. Generally speaking, there will be less liquidity when an institution's operating budget has greater reliance on the annual fund. Institutions using a large amount of fund raising to balance current expenditures may find themselves more financially vulnerable because the more money raised than is required to balance the budget, the less there will be available for growth. Moreover, this is true because the fund-raising revenue is uncertain until the end of the year.
Lenington favors sweeping all excess revenue into quasi-endowment because it (1) results in zero balance consistent with government expectation for nonprofits; (2) strengthens the balance sheet by consolidating reserves and fund balances in the quasi-endowment facilitating calculations of average endowment per student, which can help when applying for a bond issue; and (3) avoids the need to run a deficit in the current fund to use moneys contained in the fund balance. $^{13}$

\section{Current Versus Future Allocation of Surplus Revenue}

Massy's framework for achieving growth by looks at whether revenue is better spent for current use or future use. The application of Massy's framework depends to a large extent on the current state of efficiency with which the institution is operating and the subjective time discount of the strategic planners. Massy recommends "that the board should seek to maintain the existing endowment support ratio (ESR) over time unless there is a good strategic reason for changing it. Most importantly the rate should not be allowed to drift in an unmonitored fashion. Endowment support ratio is the ratio of the endowment used to support expenditures." 14

Jack Welch, the famous former chairman of General Electric, said in his autobiography, "The discipline to balance both short- and long-term is the absolute of such a strategy." "15 The hard part is the execution. The criterion for balancing when to spend or not spend the money depends on the perspectives regarding intergenerational equity. Intergenerational equity is defined as the notion that future students should enjoy the same benefits as present ones. ${ }^{16}$ 


\section{Current orientation}

Others contend that trustees should concentrate on spending money now as opposed to investing for future benefit. "A higher time-discount rate generates pressures to obtain expendable gifts for current purposes."17

Hansmann questions why gift income or any form of income is accumulated in the form of endowment rather than being spent more or less currently. ${ }^{18}$ This position is supported by the argument that it is difficult to project the needs of the future and that current spending supports future investment because current assets will continue to appreciate.

He would have universities borrow money so that buildings and programs would benefit current students. The debts could be paid through higher tuitions in the future with their higher employment capabilities, although he recognizes that allocating gift revenue to quasiendowment is a reserve against financial reversals. ${ }^{19}$ Further, he finds that temporary financial shocks affect colleges more than ordinary business firms because of:

1. Limited capability to borrow as specific assets make poor collateral;

2. Inability to sell equity;

3. Limited flexibility in adjusting scale of operations due to tenure. ${ }^{20}$

The institution needs to preserve purchasing power if it is to honor the donor's intent to support their endowed purpose in perpetuity. These considerations are even more acute when considering that Hansmann used Yale and other well-endowed medallion institutions in his study. He sampled 206 of the nation's better-endowed private colleges and found that the average institution had an endowment twice as large as its education and general expenses budget, which is not the case for the majority of small private institutions.

\section{Future orientation}

In relation to endowment accumulation, some have argued that trustees should have a zero time preference for when and how to spend revenue. Current consumption should not benefit from the prospect of future gifts to endowment.

This suggests that surplus revenue should not be spent for current use because of the belief that there will be future giving for endowment. As Tobin points out, sustainable consumption rises to encompass an enlarged scope of activities when, but not before, capital gifts enlarge the endowment. ${ }^{21}$

\section{Subjective time discount}

Massy suggests that institutional stakeholders have different time discount rates. While generally trustees have the lowest time discount rate, presidents are likely to have a very high subjective time discount. Presidents, who have relatively short tenure relative to institutional history and the high pressure to balance day-to-day operations, are often the overriding factor in determining how to spend money for current operations. This works against mitigating future financial vulnerability or enhancing future capability for growth.

In theory, the board should fund endowments when (endowment payout) spending rate exceeds their subjective time discount for utility. Further, their time discount rate should be expressed in terms of real outcomes that takes into account the expected return on capital. He states that an "investment in quasi-endowment represents the optimal strategy as long as the discount rate is less than the endowment spending rate." 22 This allows 
institutions to increase their liquidity through quasi-endowment and simultaneously reduces their financial vulnerability and increases their capacity for growth.

\section{Weaning Model}

Massy further contends that "this should lead budget and development officers to take a series of small actions to increase the flow of gifts and other additions to endowment" ${ }^{23}$ Similarly, Lenington encourages benefactors to give unrestricted funds for current operations or added to the quasi-endowment. He states that "management should be encouraged to incur excess revenues on a regular basis to accumulate quasi-endowments for reinvestment in the institution at a later time." 24 As seen in Table 2, this may be accomplished by weaning the operating budget from reliance on the annual fund.

Table 2 is an example of a model illustrating how the income stream from fund raising might be reallocated to quasiendowment to foster growth. This shows a hypothetical institution's finances over a 15-year period and indicates the degree to which the endowment would sustain the operating budget and free up additional funds for growth if unrestricted gifts were gradually allocated to quasi-endowment. The model gradually weans annual fund expenditures by $\$ 100,000$ a year and net to quasi-endowment; as the annual fund increases by $\$ 100,000$ a year, expenditures increase by $\$ 1,000,000$.

As the example illustrates, by gradually reallocating annual fund revenue from operations, the institution can significantly increase the amount of annual revenue available to it for operations. Doing this gradually allows the institution to reduce its dependency on annual giving at a comfortable percentage relative to the size of its expenditure budget. The significant increase in quasi-endowment ameliorates financial vulnerability by increasing the

Table 2: Hypothetical weaning model

\begin{tabular}{llllllr}
\hline Year & $\begin{array}{l}\text { Expenditures } \\
(\$)\end{array}$ & $\begin{array}{l}\text { Annual fund } \\
(\$)\end{array}$ & $\begin{array}{l}\text { Annual fund } \\
(\$)\end{array}$ & $\begin{array}{l}\text { Annual fund } \\
\text { for quasi- } \\
\text { endowment } \mathbf{( \$ )}\end{array}$ & $\begin{array}{l}\text { Cumulative } \\
\text { QE* } \mathbf{( \$ )}\end{array}$ & $\begin{array}{l}\text { QE } \\
\text { payout*** } \\
\mathbf{( \$ )}\end{array}$ \\
\hline 1 & $20,000,000$ & $1,000,000$ & 900,000 & 100,000 & 100,000 & \\
2 & $21,000,000$ & $1,100,000$ & 800,000 & 300,000 & 405,000 & 5,000 \\
3 & $22,000,000$ & $1,200,000$ & 700,000 & 500,000 & 925,250 & 20,250 \\
4 & $23,000,000$ & $1,300,000$ & 600,000 & 700,000 & $1,671,513$ & 46,263 \\
5 & $24,000,000$ & $1,400,000$ & 500,000 & 900,000 & $2,655,088$ & 83.576 \\
6 & $25,000.000$ & $1,500,000$ & 400,000 & $1,100,000$ & $3,887,843$ & 132.754 \\
7 & $26,000,000$ & $1,600,000$ & 300,000 & $1,300,000$ & $5,382,235$ & 194,392 \\
8 & $27,000,000$ & $1,700,000$ & 200,000 & $1,500,000$ & $7,151,346$ & 269,112 \\
9 & $28,000,000$ & $1,800,000$ & 100,000 & $1,700,000$ & $9,208,914$ & 357,567 \\
10 & $29,000,000$ & $1,900,000$ & - & $1,900,000$ & $11,569,369$ & 460,446 \\
11 & $30,000,000$ & $2,000,000$ & - & $2,000,000$ & $14,147,827$ & 578,468 \\
12 & $31,000,000$ & $2,100,000$ & - & $2,100,000$ & $16,955,219$ & 707,391 \\
13 & $32,000,000$ & $2,200,000$ & - & $2,200,000$ & $20,002,980$ & 847,761 \\
14 & $33,000,000$ & $2,300,000$ & - & $2,300,000$ & $23,303,129$ & $1,000,149$ \\
15 & $34,000,000$ & $2,400,000$ & - & $2,400,000$ & $26,868,285$ & $1,165,156$ \\
\hline
\end{tabular}

* Assumes a 10 percent total rate of return

** Assumes a 5 percent spending policy 
flow of available revenue. Moreover, because the revenues are put into quasiendowment, the institution can spend the principal if necessary.

This example showed an institution that increased the expenditures and the amount of annual funds each year. A similar chart could be constructed for a static amount, but the time frames would have to be increased or the expenditures reduced. Different institutions may adopt the model to fit their own circumstances.

Maniaci, Poole, and Wilson found that institutions increased tuition dependency when they had 4 percent or more of their budgets provided by the annual fund and a decrease in dependency when the annual payout rose above 4 percent. ${ }^{25}$ Maniaci and Poole created a taxonomy, called the vulnerability model (see Figure 2), based on those benchmarks, where institutions are categorized by their degree of reliance on the annual fund and on the endowment payout relative to the operational budget. $^{26}$

The vulnerability model integrated Massey's three methods of generating surplus revenue into a single framework which allows trustees and administrators to identify the appropriate environment in which to emphasize one method or another. ${ }^{27}$ Maniaci and Poole (2004) concluded:

By determining what percentage of the operating budget is paid for by the annual fund and the payout from endowment and thus categorizing their budgetary environment to the vulnerability framework, institutions will be better served in their strategic planning both in conducting a situational analysis and aligning their operating budget with their mission and vision. This framework defines four quadrants in a taxonomy of strategic budgetary environment based on vulnerability. ${ }^{28}$

The Maniaci-Poole Vulnerability Model can also be looked at as an integrated surplus revenue model that describes four quadrants: when to use each of Massey's three surplus revenue generating models and the ideal situation. The institutions weaning the annual funds from operations to quasi-endowment will change their position over time from one quadrant of the vulnerability model to another.

Category I institutions have sufficient funds for current operations without relying on either the annual fund or endowment payouts. While stable today, they need to raise additional funds for future operations. These institutions can plan for the future by raising money and placing it directly in the quasi-endowment until such time as the endowment payout provides funding for future operations.

Category II institutions are in a slightly worse condition, compared with Category

\begin{tabular}{|c|c|}
\hline II & $\begin{array}{c}\text { IV } \\
\text { High annual fund } \\
\text { Low endowment }\end{array}$ \\
$\begin{array}{c}\text { I } \\
\text { Low annual fund } \\
\text { Low endowment }\end{array}$ & High endowment \\
\hline
\end{tabular}

Figure 2: Maniaci-Poole vulnerability model 


\begin{tabular}{|c|c|}
\hline $\begin{array}{c}\text { II } \\
\text { Unstable today } \\
\text { Emphasize reallocating revenues } \\
\text { for future operations }\end{array}$ & $\begin{array}{c}\text { IV } \\
\text { Unstable today } \\
\text { Emphasizes future costs }\end{array}$ \\
\hline $\begin{array}{l}\text { I } \\
\text { Stable today } \\
\text { Emphasize revenue for } \\
\text { future operations }\end{array}$ & $\begin{array}{l}\text { III } \\
\text { Stable today and future } \\
\text { ideal situation }\end{array}$ \\
\hline
\end{tabular}

Figure 3: Integrated surplus revenue model

I organizations, as they are already raising annual fund contributions. This situation is ideal for the weaning model. They have to reallocate current revenues and become more efficient.

The ideal situation is in quadrant III, where the operating budget has a strong endowment payout and does not rely heavily on the annual fund. This situation provides enough revenue for current operations while allowing for future expansion. This quadrant represents the goal for institutions that use the weaning method.

Category IV organizations have a large endowment payout which allows them to get lazy. They should look to pare expenses, as they are already receiving a high percentage of their budget from the annual fund, even though they also have a continuing stream of revenue from their endowment payout. Failure to reduce their expenses will eventually impact their operations.

\section{Conclusion}

The purpose of this paper is to discuss how private master degree granting universities can become more efficient by strategically planning for surplus in gifts for current operations and by investing that surplus in endowment. Different institutions operate at different levels of efficiency and require different approaches.
Zemsky and Massey described three separate models used to balance budgets, each of which should be used in the annual budget process: decreased cost, increased revenue, and reallocation of resources. ${ }^{29}$ This paper provides examples of each approach. Further, we state that each approach can be successful to balance the budget; however, efficiency can be improved by cost reduction and resource allocation, whereas increasing revenue tends to dull the incentive to increase efficiency.

The degree of efficiency determines the environmental situational analysis which the boards and institutional administrations face. Strategic planning requires organizations to look at not just current but future obligations. Balancing the needs of the present, in order to fund the future desires, requires a link to the mission and vision of the institution. This link can only occur at the board level.

Maniaci and Poole integrated Zemsky and Massey's three approaches into a single model. By noting the environmental situation that their institution faces, the Maniaci-Poole Vulnerability model provides a starting point to determine which approach to use. They further describe the ideal situation balancing both current and future obligations, which provides an endpoint for strategic change. ${ }^{30}$

This paper provides a roadmap for that 
strategic planning process. The authors describe how institutions can become more efficient by weaning away from reliance from annual fund contributions and increasing the quasi-endowment. In doing so, institutions can shift from their existing situational environmental quadrant to the ideal situation.

\section{References}

1. National Center for Educational Statistics (2001), Post Secondary Education, Department of Education, Washington DC, Chapter 3, Table 246.

2. R. Lenington (1996), Managing Higher Education as a Business, American Council on Education/Oryx Press, Phoenix AZ, p. 9.

3. R. Zemsky and W. F. Massey (1995), "Expanding perimeters, melting cores and sticky functions: toward an understanding of our current predicaments," Change, 27, pp. 41-9.

4. Higher Education Price Index (2000), Research Associates of Washington, Washington, DC

5. Zemsky and Massey (1995), "Expanding perimeters, melting cores and sticky functions," op. cit.

6. H. Tuckman and C. Chang (1992), "Nonprofit equity: a behavioral model and its policy implications," Journal of Policy and Analysis and Management, 111, 1, pp. 76-87.

7. Ibid., p. 77.

8. Ibid., p. 79

9. H Tuckman and C. Chang (1991), "Why do nonprofit managers accumulate surpluses and how much do they accumulate?" Nonprofit Management and Leadership, 91, p. 123.

10. R. A. Lefrancois (1984), "Challenge for the 1990s: productivity-oriented university management," Cost and Management, 58,1, p. 58

11. H. R. Bowen (1970), Financial Needs of the Campus: The Corporation and the Campus, New York Academy of Political Science, New York.

12. Tuckman and Chang (1991), "Why do nonprofit managers accumulate surpluses and how much do they accumulate?" op. cit., p. 123.

13. Lenington (1996), Managing Higher Education as a Business, op. cit.

14. W. F. Massey (1996), Resource Allocation in Higher Education: Who Should Pay, Johns Hopkins University Press, Baltimore, p. 133.

15. J. Welch (2001), Jack: Straight from the Gut, Warner Books, New York.

16. Massey (1996), Resource Allocation in Higher Education, op. cit.

17. Ibid., p. 120.

18. H. Hansmann (1990), "Why do universities have endowment," Journal of Legal Studies, 19, 1, pp. 3-42.

19. Ibid., p. 21.

20. Ibid., p. 22.

21. J. Tobin (1974), "What is permanent endowment income?" The American Economic Review, 64, 2, pp. 427-32, see p. 427.

22. Massey (1996), Resource Allocation in Higher Education, op. cit., p. 120.

23. Ibid., p.133.

24. Lenington (1996), Managing Higher Education as a Business, op. cit., p. 85.

25. V. M. Maniaci, R. Poole, and T. L. Wilson (2003), "The relationship of annual giving and endowment payout to future tuition dependency at private master's universities," CASE International Journal of Educational Advancement, 4, 2, pp. 115-25.

26. V. M. Maniaci and R. Poole, (2004), “An integrated model of generating surplus revenue using the vulnerability framework," The International Journal of Educational Advancement, 5, 1, pp. 76-84.

27. Massey (1996), Resource Allocation in Higher Education, op. cit., p. 120.

28. Maniaci and Poole (2004), "An integrated model of generating surplus revenue using the vulnerability framework,” op. cit., p. 83.

29. Zemsky and Massey (1995), "Expanding perimeters, melting cores and sticky functions," op. cit.

30. Maniaci and Poole (2004), "An integrated model of generating surplus revenue using the vulnerability framework," op. cit.

\section{Practitioner's Perspective}

In a thorough review of the literature, Maniaci and Poole outline reasons why institutions tend toward increasing reliance on current unrestricted fund raising (lack of strategic alignment, inefficient resource allocation, intense competition in the higher education market, and a bias toward current versus future expendituresespecially by presidents who have limited time at an institution). While practitioners are all too aware of these pressures, Vincent Maniaci and Rob Poole build on their earlier research (with Thomas L. Wilson) to establish that there are good reasons to 
resist those pressures and to present practitioners with a model to reduce their institutions' reliance on the annual fund to meet current operations expenses.

Maniaci, Poole, and Wilson (2003) established that institutions which relied on annual fund revenue to supply greater than 4 percent of current operations tended to become more tuition-dependent over time. Maniaci and Poole argue that institutions should take the long view and work toward becoming less tuition-dependent by developing significant reserves in the form of quasi-endowment. These reserves then produce income to offset the decreased use of the annual fund and at the same time protect the institution against fluctuations in enrollment, market returns, and fund raising. Few would argue against the benefit of attaining such institutional resilience, yet most seem unable or unwilling to move in that direction.

Maniaci and Poole suggest that an institution can and should increase the amount of annual unrestricted support raised each year, and that at the same time the institution can and should decrease the amount of annual unrestricted support allocated to current operations to zero incrementally over a period of years. Each year both the increase in the amount raised and the decrease in the amount spent would be, in their model, allocated to quasi-endowment. In time, there is no need for current unrestricted support because income on the quasi-endowment is adequate to meet the needs of the institution. Certainly this model proposes an ideal for institutions to consider.

There are certainly questions remaining for further research. Is it possible to continuously increase the amount raised for current operations while at the same time demonstrating a reduced reliance on such funds? How does an institution decide whether an investment in quasi-endowment is more efficient and/or effective than investing those resources in increasing quality or capacity once the institution is spending less than 4 percent of its annual fund on operations? Is it possible to achieve similar ends by achieving smaller surpluses in unrestricted funds while emphasizing restricted fund raising to reduce dependency over time-especially since restricted fund raising tends to be more cost effective? These questions may need to be answered to effectively counterbalance the ever-present demand for increased spending on current operations.

Practitioners should certainly take to heart the relationship between reducing dependency on the annual fund for current operations as a means to decrease tuition dependency in the long term. Maniaci and Poole present both compelling rationale and a means to the desired end. Small private colleges and universities must certainly find a way to become less tuition-dependent over time, or many more will be relegated to the dustbin of history in the years ahead.

Dan Struble, Ph.D. President, Montreat College, Montreat, North Carolina 